\title{
Confluence does not affect the expression of miR-375 and its direct targets in rat and human insulin-secreting cell lines
}

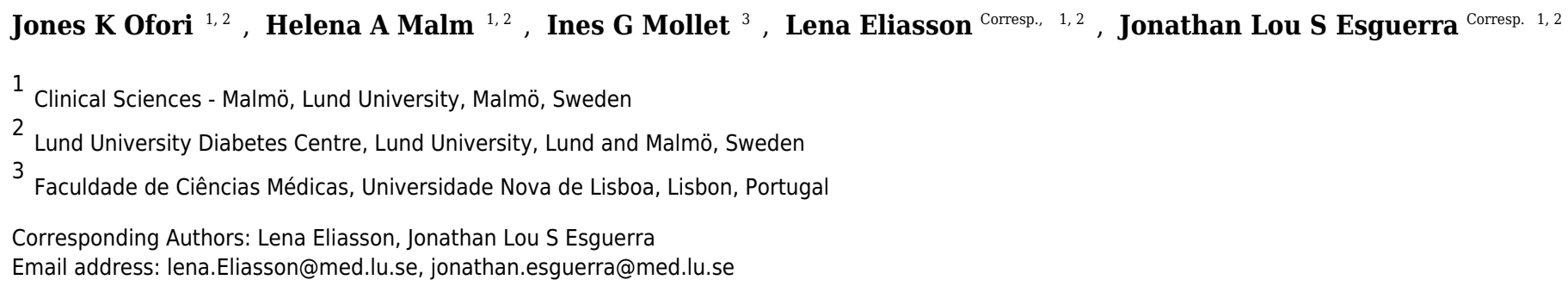

MicroRNAs are small non-coding RNAs, which negatively regulate the expression of target genes. They have emerged as important modulators in beta cell compensation upon increased metabolic demand, failure of which leads to reduced insulin secretion and type 2 diabetes. To elucidate the function of miRNAs in beta cells, insulin-secreting cell lines, such as the rat insulinoma INS-1 832/13 and the human EndoC- $\mathrm{BH} 1$, are widely used. Previous studies in the cancer field have suggested that miRNA expression is influenced by confluency of adherent cells. We therefore aimed to investigate whether one of the most enriched miRNAs in the pancreatic endocrine cells, miR-375, and two of its validated targets in mouse, Cav1 and Aifm1, were differentially-expressed in cell cultures with different confluences. Additionally, we measured the expression of other miRNAs, such as miR-152, miR-130a, miR-132, miR-212 and miR-200a, with known roles in beta cell function. We did not see any significant expression changes of miR-375 nor any of the two targets, in both the rat and human beta cell lines at different confluences. Interestingly, among the other miRNAs measured, the expression of miR-132 and miR-212 positive correlated with confluence but only in the INS-1 832/13 cells. Our results show that the expression of miR-375 and other miRNAs with known roles in beta cell function is independent of, or at least minimally influenced by the density of proliferating adherent cells, especially within the confluence range optimal for functional assays to elucidate miRNA-dependent regulatory mechanisms in the beta cell. 
1 Confluence does not affect the expression of miR-375 and its direct targets in 2 rat and human insulin-secreting cell lines

3 Jones K Ofori ${ }^{\S 1}$, Helena A Malm ${ }^{\S 1}$, Inês G. Mollet ${ }^{2}$, Lena Eliasson ${ }^{1 *}$, Jonathan LS Esguerra ${ }^{1 *}$

$5 \quad{ }^{1}$ Unit of Islet Cell Exocytosis, Department of Clinical Sciences Malmö, Lund University 6 Diabetes Centre, Lund University CRC 91-11, Jan Waldenströms gata 35, 20502 Malmö,

7 Sweden

8 2Metabolic Disorders Unit, Faculdade de Ciências Médicas, Universidade Nova de Lisboa, Rua

9 Câmara Pestana n ${ }^{\circ}$, Edifício CEDOC II, 1150-082, Lisbon, Portugal

10 \$These authors contributed equally.

11 *Address for correspondence:

12 Lena Eliasson and Jonathan LS Esguerra, email: lena.eliasson@med.lu.se and

13 jonathan.esguerra@med.lu.se 


\section{ABSTRACT}

17 MicroRNAs are small non-coding RNAs, which negatively regulate the expression of target

18 genes. They have emerged as important modulators in beta cell compensation upon increased

19 metabolic demand, failure of which leads to reduced insulin secretion and type 2 diabetes. To elucidate the function of miRNAs in beta cells, insulin-secreting cell lines, such as the rat insulinoma INS-1 832/13 and the human EndoC- $\beta$ H1, are widely used. Previous studies in the cancer field have suggested that miRNA expression is influenced by confluency of adherent cells. We therefore aimed to investigate whether one of the most enriched miRNAs in the pancreatic endocrine cells, miR-375, and two of its validated targets in mouse, Cav1 and Aifm1, were differentially-expressed in cell cultures with different confluences. Additionally, we measured the expression of other miRNAs, such as miR-152, miR-130a, miR-132, miR-212 and miR-200a, with known roles in beta cell function. We did not see any significant expression changes of miR-375 nor any of the two targets, in both the rat and human beta cell lines at different confluences. Interestingly, among the other miRNAs measured, the expression of miR132 and miR-212 positive correlated with confluence but only in the INS-1 832/13 cells. Our results show that the expression of miR-375 and other miRNAs with known roles in beta cell function is independent of, or at least minimally influenced by the density of proliferating adherent cells, especially within the confluence range optimal for functional assays to elucidate miRNA-dependent regulatory mechanisms in the beta cell. 
37

38

\section{Introduction}

Type-2 diabetes (T2D) is a complex metabolic disease characterized by elevated blood glucose levels due to a combination of insulin resistance and impaired insulin secretion (Prasad \& Groop 2015). Western life-style with reduced exercise and unhealthy food-habits result in insulin resistance in target tissues such as in liver, muscle and adipose tissue. To cope with increased metabolic demands, pancreatic beta cells secrete more insulin. Failure to compensate contributes to the development of T2D (Halban et al. 2014). By regulating various cellular processes within the beta cell, microRNAs (miRNAs) have been suggested to play important roles in rapid compensatory response to changing environments (Eliasson \& Esguerra 2014; Esguerra et al. 2014).

MiRNAs are small non-coding RNAs involved in the regulation of gene expression. They bind to the 3'UTR of the target mRNA leading to mRNA degradation and/or translational repression (Bartel 2009). In diabetes, several miRNAs have been shown to be differentially expressed and have been shown to be involved in important beta cell functions and in maintaining beta cell mass (Esguerra et al. 2014; Poy et al. 2009).

The first miRNA discovered in the pancreatic islet cells was miR-375 (Poy et al. 2004), which is one of the most highly-enriched miRNAs in the pancreatic islets. Since its discovery, miR-375 has been shown to negatively regulate a plethora of genes involved in pancreatic beta cell function (Eliasson 2017) such as in insulin secretion by regulating myotrophin (Mtpn) (Poy et al. 2004) and various voltage-gated sodium channels (SCNs) (Salunkhe et al. 2015). Knock out of miR-375 in mouse $(375 \mathrm{KO})$, resulted in hyperglycaemic animals with defective proliferative capacity of endocrine cells leading to decreased beta cell mass (Poy et al. 2009). Studies on islets of $375 \mathrm{KO}$ mice reveal direct regulation of multiple genes involved in the negative control of cellular growth and proliferation such as the apoptosis-inducing factor, mitochondrion-associated 1 (Aifml) and caveolin1 (Cavl) (Poy et al. 2009).

Another highly-enriched beta cell miRNA is miR-200a, demonstrated to be upregulated in islets of the $\mathrm{db} / \mathrm{db}$ diabetic mouse model and shown to contribute in regulating pancreatic beta cell survival in T2D (Belgardt et al. 2015). There are also a number of miRNAs such as miR-132, miR-212, miR-130a and miR-152 shown to be upregulated in the pancreatic islets of the widely- 
66

67

68

69

70

studied T2D model Goto-Kakizaki rats (Esguerra et al. 2011) with active roles in beta cell stimulus-secretion coupling (Malm et al. 2016; Ofori et al. 2017).

Cell lines are commonly utilized to unravel the molecular mechanisms by which miRNAs participate in cellular processes. The ease of handling, maintenance and availability of cell line models make them indispensable tools in molecular biology investigations. Indeed, studying molecular mechanisms underlying fundamental beta cell processes such as the stimulus-secretion coupling have been made possible by tumour-derived rat insulin-secreting cell lines such as INS1 (Asfari et al. 1992), and its more recent derivative sub-line, INS-1 832/13 cells (Hohmeier et al. 2000). Recently, the human beta cell line EndoC- $\beta$ H1 has also been made available which further enabled deeper investigations of molecular mechanisms governing insulin secretion in humans (Andersson et al. 2015; Ravassard et al. 2011).

It has been noticed that the global abundance of miRNAs is generally lower in cell lines than in primary tissues of cancer ( $\mathrm{Lu}$ et al. 2005). One hypothesis is that the tight cell-cell contacts in primary tissues contribute to the activation of miRNA biogenesis. Indeed, it was shown that higher cellular density or confluence resulted in higher levels of various miRNAs in HeLa and NIH3T3 cells (Hwang et al. 2009; van Rooij 2011). Because many functional assays, e.g. insulin secretion assay, being performed on beta cell lines require optimal culture conditions including cell densities, we therefore set out to investigate whether confluence affects the expression of miR-375 and two of its validated targets in the mouse beta cell, Aifm 1 and Cav1, in the rat INS$1832 / 13$ cells and in the human EndoC- $\beta \mathrm{H} 1$ cells. We also investigated the influence of confluence on the expression levels of miR-200a, miR-130a, miR-152, miR-132 and miR-212.

\section{Materials \& Methods}

Reagents

All reagents were purchased from Sigma Aldrich (MO, USA) unless otherwise stated.

\section{Cell culture, seeding and imaging}

EndoC- $\beta \mathrm{H} 1$ cells (EndoCells, Paris, France) (Andersson et al. 2015; Ravassard et al. 2011) (passages between 76-80) were seeded on 24-well plates coated with Matrigel-fibronectin (100 $\mu \mathrm{g} / \mathrm{mL}$ and $2 \mu \mathrm{g} / \mathrm{mL}$, Sigma-Aldrich, Steinheim, Germany) at the following densities: 390,000 cells/well, 312,000 cells/well, 234,000 cells/well and 78,000 cells/well to reach $100 \%, 80 \%, 60 \%$ 
95

96

97

98

99

100

101

102

103

104

105

106

107

108

109

110

111

112

113

114

115

116

117

118

119

120

121

122

123

124

125

and $20 \%$ estimated confluence respectively after 48 hours. The cells were maintained in a culture medium containing: DMEM (5.6 mM glucose), 2\% BSA fraction V (Roche Diagnostics, Mannheim, Germany), 10 mM nicotinamide (Merck Millipore, Darmstadt, Germany), $50 \mu \mathrm{M} 2$ mercaptoethanol, $5.5 \mu \mathrm{g} / \mathrm{mL}$ transferrin, $6.7 \mathrm{ng} / \mathrm{mL}$ sodium selenite (Sigma-Aldrich), $100 \mathrm{U} / \mathrm{mL}$ penicillin, and $100 \mu \mathrm{g} / \mathrm{mL}$ streptomycin (PAA Laboratories, Pasching, Austria).

Rat insulinoma INS-1 832/13 cells (passages between 50-55) (Hohmeier et al. 2000) were seeded accordingly: 300,000 cells/well, 240,000 cells/well, 180,000 cells/well and 60,000 cells/well to reach $100 \%, 80 \%, 60 \%$ and $20 \%$ estimated confluence respectively after 48 hours. The growth area per well in the 24 well plate is $1.9 \mathrm{~cm}^{2}$. Cells were maintained in RPMI 1640 medium containing $11.1 \mathrm{mM}$ glucose (HyClone, UT, USA) as previously described (Salunkhe et al. 2015). Both cell lines were incubated in a humidified atmosphere with $5 \% \mathrm{CO} 2$ at $37^{\circ} \mathrm{C}$ for 48 hours. All experiments were performed within culture passages in which the cell lines respond robustly to glucose-stimulated insulin secretion assay.

To measure cell-to-cell contact, $300 \mathrm{uL}$ suspension of EndoC- $\beta \mathrm{H} 1$ cells were seeded on microscope slides with 8 chambered wells (growth area per well: $1.0 \mathrm{~cm}^{2}$ ) (Cat. No. 80827, ibidi Gmbh, Germany). The corresponding seeding cell densities for each estimated harvest confluency were as follows: $20 \%$ confluence: 41,053 cells $/ \mathrm{cm}^{2} ; 60 \%$ confluence: 123,158 cells/ $\mathrm{cm}^{2} ; 80 \%$ confluence: 1642,10 cells/ $\mathrm{cm}^{2} ; 100 \%$ confluence: 205,263 cells $/ \mathrm{cm}^{2}$. The seeded cells were imaged at 40X magnification on a Zeiss LSM 510 microscope. Cell-to-cell distances between randomly selected cells were measured $(n=40-90)$ and averaged. See Supplemental Fig. S1 for representative image panels with distance measurements.

\section{$R N A$ extraction, $R T-P C R$ and $q P C R$}

RNA extraction, RT-PCR for total RNA and stem-loop RT-qPCR for microRNA was performed as previously described (Salunkhe et al. 2015) using the following TaqMan ${ }^{\circledR} \operatorname{miRNA}$ Assays: miR-375 (RT_000564), miR-200a (RT_000502), miR-130a (RT_000454), miR-152 (RT_000475), miR-132 (RT_000457), miR-212 (RT_002551), rat U87 (RT_001712), human RNU44 (RT_001094) and human RNU48 (RT_001006) for generating cDNA. The following primers from TaqMan ${ }^{\circledR}$ Gene Expression and TaqMan ${ }^{\circledR}$ MiRNA. Assays were used for qPCR: Cav1/CAV1 (Rn00755834_m1/Hs00971716_m1), Aifm1/AIFM1 (Rn00442540_m1/ Hs00377585_m1), miR-375 (TM_000564), miR-200a (TM_000502), miR-130a (TM_00454), 
126

127

128

129

130

131

132

133

134

135

136

137

miR-152 (TM_000475), miR-132 (TM_000457) and miR-212 (TM_002551) were used for qPCR. Hprt1/HPRT1 (Rn_01527840/4333768F) and Ppia/PPIA (Rn_00690933/4333763F)

were used as endogenous controls for mRNA expression, while rat U87 (TM_001712) or human RNU44 (TM_001094) and human RNU48 (TM_001006) were used as endogenous control for miR-375 expression. The relative quantities were calculated using the $\Delta \Delta \mathrm{Ct}$ method. The average $\mathrm{Ct}$ values of qPCR assays for each duplicate or triplicate runs are provided in Supplemental Table S1.

\section{Statistical Analysis}

Differences between groups were tested using one-way ANOVA followed by Tukey's multiple comparison test as implemented in GraphPad Prism 7. Data are presented as means $\pm \mathrm{SEM}$.

\section{Results \& Discussion}

To find out the influence of cell confluence on the expression of selected miRNAs and targets, we utilized the rat (INS-1 832/13) and human (EndoC- $\beta$ H1) insulin-secreting cell lines seeded at different cell densities, followed by gene expression measurements (Fig. 1A). To quantify the cell-to-cell contact, we also seeded EndoC- $\beta \mathrm{H} 1$ cells in parallel, at different densities corresponding to each confluence harvest point. We measured on average $30 \mu \mathrm{m}$ between cells in $100 \%$ confluent plates, while the lowest $20 \%$ confluent plates contained cells with an average of $140 \mu \mathrm{m}$ cell-to-cell distance (Fig. 1B and Supplemental Fig. S1).

This study mainly addressed the issue whether confluence affects miR-375 expression, as it is one of the most enriched miRNAs in the pancreatic beta cells influencing diverse molecular processes, from insulin secretion to cellular growth and proliferation (Eliasson 2017; Poy et al. 2004; Poy et al. 2009; Salunkhe et al. 2015). The genes Aifml and Cavl are among the many genes shown to be directly targeted by miR-375 in mouse beta cells. The negative effect of miR375 on both the mRNA and protein levels of the two genes has been demonstrated, and in the islets of $375 \mathrm{KO}$ mice, increased expression of these targets was also detected at the mRNA level (Poy et al. 2009). Aifm 1 and Cavl are involved in signaling mechanisms that negatively regulate cellular growth and proliferation, hence $375 \mathrm{KO}$ mice were found to have reduced beta cell mass and defective proliferative capacity in the pancreatic endocrine cells (Poy et al. 2009). 
154 In the rat insulin-secreting cell line, INS-1 832/13, we previously showed the reduction of Aifm 1 155 and Cav1 mRNA expression upon miR-375 over-expression delineating the conserved targeting 156 in rodents of these genes by miR-375 (Salunkhe et al. 2015). In humans, computational 157 predictions show that miR-375 has two non-conserved target sites in the 3'UTR of AIFMI 158 mRNA (Target Scan v.7.1 release June 2016) (Agarwal et al. 2015), and one target site in the 159 CAV1 3'UTR identified by another miRNA target prediction program (RNA22 algorithm 160 implemented at miRWalk 2.0) (Dweep \& Gretz 2015).

161 In INS-1 832/13 cells, we did not detect any significantly altered expression of neither miR-375

162

163

164

165

166

167

168

169

170

171

172

173

174

175

176

177

178

179

180

181

182

183

nor its targets among the different confluences (Fig. 2A-C). Likewise in the human EndoC- $\beta \mathrm{H} 1$ cells, the expression of miR-375 was similar at all confluences (Fig. 3D). Interestingly, we observed slightly decreased expression of $C A V 1 \mathrm{mRNA}$ at $60 \%$ and $100 \%$ confluence compared to the $20 \%$ confluence (Fig. $3 \mathrm{~F}$ ). Although miR-375 is also predicted to target CAV1 3'UTR mRNA, miR-375 expression was not elevated at higher confluences, implying that $C A V 1 \mathrm{mRNA}$ is potentially regulated by other factors. These results further underline the impact of speciesspecific effects of miRNA-mediated regulation in cellular processes.

Among the other miRNAs included in this study, we observed significantly higher expression levels of miR-132 and miR-212 at higher confluences in INS-1 832/13 cells (Fig. 3A-B) but only an increasing trend in the human EndoC- $\beta$ H1 cells (Fig. 3C-D). For miR-200a, miR-130a and miR-152, the expression levels were found not to be influenced by cellular confluence (Supplemental Fig. S2). However, although not significant, we observed a trend of increasing miRNA expression from $20 \%$ to higher confluences in the EndoC- $\beta$ H1 cells (Supplemental Fig. S2D-F). Overall, the pattern of increased miRNA expression with increasing confluence in this study, supports previous observation of increased activation of miRNA biogenesis and expression at higher cellular densities (Hwang et al. 2009; van Rooij 2011).

\section{Conclusion}

We found virtually no significant differences in the expression levels of miR-375, CAV1 mRNA and AIFM1 mRNA at higher confluences, from $60 \%-100 \%$, either in the rat or human beta cell lines. Moreover, we did not find significant differences in the expression of the other miRNAs tested in either INS-1 832/13 or EndoC- $\beta \mathrm{H} 1$ cells between $80 \%$ and $100 \%$ confluence. These results are comforting because most functional assays employing pancreatic beta cell lines utilize 
184 these confluence levels to attain consistent results. For instance, to ensure optimal insulin 185 secretion in cultured beta cell lines, insulin-secretion assays are commonly performed when the 186 cell culture confluence is at least $90 \%$.

187 Although we showed that miR-375, which is one of the most enriched beta cell miRNA was not

188

189

190

191

192

193

194

195

196

197

198

199

200

201

202

203

204

205

206

207

208

209

210

211

212

213

significantly influenced by confluence level in cultured rat and human beta cell lines, we clearly demonstrated that miR-132 and miR-212 are more dependent on cellular densities, as was shown for some miRNAs in other cells types (Hwang et al. 2009; van Rooij 2011). One must therefore be cautious in controlling for cell densities when investigating specific miRNAs in in vitro systems.

It has been observed that primary tissues generally exhibit higher global miRNA abundance compared to cell lines in part attributed to tighter, and greater cell-to-cell contact in threedimensions ( $\mathrm{Lu}$ et al. 2005). Nevertheless, it remains to be seen in the pancreatic endocrine cells how the three-dimensional organization of the cells impacts the global miRNA expression and hence, the regulation of various cellular processes.

\section{Acknowledgment}

We thank Britt-Marie Nilsson and Anna Maria V Ramsay for the technical support. Special acknowledgment to R. Scharfmann and P. Ravassard, INSERM and ENDOCELL for providing us with the EndoC- $\beta \mathrm{H} 1$ human beta cell line, and C. Newgard and H. Mulder for providing us with the INS-1 832/13 cells. This work was supported by the Swedish Research Council (Research project: LE); Linnaeus grant to LUDC; SFO-EXODIAB, Region Skåne-ALF, The Swedish Diabetes Foundation, Albert Påhlsson Foundation, The Crafoord Foundation, Magnus Bergvalls Stiftelse, and The Edla and Eric Smedberg Foundation Fund thru The Royal Physiographic Society of Lund.

\section{References}

Agarwal V, Bell GW, Nam JW, and Bartel DP. 2015. Predicting effective microRNA target sites in mammalian mRNAs. Elife 4. 10.7554/eLife.05005

Andersson LE, Valtat B, Bagge A, Sharoyko VV, Nicholls DG, Ravassard P, Scharfmann R, Spegel P, and Mulder H. 2015. Characterization of stimulus-secretion coupling in the human pancreatic EndoC-betaH1 beta cell line. PLoS One 10:e120879. 10.1371/journal.pone.0120879 
214

215

216

217

218

219

220

221

222

223

224

225

226

227

228

229

230

231

232

233

234

235

236

237

238

239

240

241

242

243

244

245

246

247

248

249

Asfari M, Janjic D, Meda P, Li G, Halban PA, and Wollheim CB. 1992. Establishment of 2mercaptoethanol-dependent differentiated insulin-secreting cell lines. Endocrinology 130:167-178. 10.1210/endo.130.1.1370150

Bartel DP. 2009. MicroRNAs: target recognition and regulatory functions. Cell 136:215-233. 10.1016/j.cell.2009.01.002

Belgardt BF, Ahmed K, Spranger M, Latreille M, Denzler R, Kondratiuk N, von Meyenn F, Villena FN, Herrmanns K, Bosco D, Kerr-Conte J, Pattou F, Rulicke T, and Stoffel M. 2015. The microRNA-200 family regulates pancreatic beta cell survival in type 2 diabetes. Nat Med 21:619-627. 10.1038/nm.3862

Dweep H, and Gretz N. 2015. miRWalk2.0: a comprehensive atlas of microRNA-target interactions. Nat Methods 12:697. 10.1038/nmeth.3485

Eliasson L. 2017. The small RNA miR-375 - a pancreatic islet abundant miRNA with multiple roles in endocrine beta cell function. Mol Cell Endocrinol. 10.1016/j.mce.2017.02.043

Eliasson L, and Esguerra JL. 2014. Role of non-coding RNAs in pancreatic beta-cell development and physiology. Acta Physiol (Oxf) 211:273-284. 10.1111/apha.12285

Esguerra JL, Bolmeson C, Cilio CM, and Eliasson L. 2011. Differential glucose-regulation of microRNAs in pancreatic islets of non-obese type 2 diabetes model Goto-Kakizaki rat. PLoS One 6:e18613. 10.1371/journal.pone.0018613

Esguerra JL, Mollet IG, Salunkhe VA, Wendt A, and Eliasson L. 2014. Regulation of Pancreatic Beta Cell Stimulus-Secretion Coupling by microRNAs. Genes (Basel) 5:1018-1031. 10.3390/genes5041018

Halban PA, Polonsky KS, Bowden DW, Hawkins MA, Ling C, Mather KJ, Powers AC, Rhodes CJ, Sussel L, and Weir GC. 2014. beta-cell failure in type 2 diabetes: postulated mechanisms and prospects for prevention and treatment. Diabetes Care 37:1751-1758. $10.2337 / \mathrm{dc} 14-0396$

Hohmeier HE, Mulder H, Chen G, Henkel-Rieger R, Prentki M, and Newgard CB. 2000. Isolation of INS-1-derived cell lines with robust ATP-sensitive $\mathrm{K}+$ channel-dependent and -independent glucose-stimulated insulin secretion. Diabetes 49:424-430.

Hwang HW, Wentzel EA, and Mendell JT. 2009. Cell-cell contact globally activates microRNA biogenesis. Proc Natl Acad Sci U S A 106:7016-7021. 10.1073/pnas.0811523106

Lu J, Getz G, Miska EA, Alvarez-Saavedra E, Lamb J, Peck D, Sweet-Cordero A, Ebert BL, Mak RH, Ferrando AA, Downing JR, Jacks T, Horvitz HR, and Golub TR. 2005. MicroRNA expression profiles classify human cancers. Nature 435:834-838. 10.1038/nature03702

Malm HA, Mollet IG, Berggreen C, Orho-Melander M, Esguerra JL, Goransson O, and Eliasson L. 2016. Transcriptional regulation of the miR-212/miR-132 cluster in insulin-secreting 
252

253

254

255

256

257

258

259

260

261

262

263

264

265

266

267

268

269

270

271

272

beta-cells by cAMP-regulated transcriptional co-activator 1 and salt-inducible kinases. Mol Cell Endocrinol 424:23-33. 10.1016/j.mce.2016.01.010

Ofori JK, Salunkhe VA, Bagge A, Vishnu N, Nagao M, Mulder H, Wollheim CB, Eliasson L, and Esguerra JL. 2017. Elevated $\mathrm{miR}-130 \mathrm{a} / \mathrm{miR} 130 \mathrm{~b} / \mathrm{miR}-152$ expression reduces intracellular ATP levels in the pancreatic beta cell. Sci Rep 7:44986. 10.1038/srep44986

Poy MN, Eliasson L, Krutzfeldt J, Kuwajima S, Ma X, Macdonald PE, Pfeffer S, Tuschl T, Rajewsky N, Rorsman P, and Stoffel M. 2004. A pancreatic islet-specific microRNA regulates insulin secretion. Nature 432:226-230. 10.1038/nature03076

Poy MN, Hausser J, Trajkovski M, Braun M, Collins S, Rorsman P, Zavolan M, and Stoffel M. 2009. miR-375 maintains normal pancreatic alpha- and beta-cell mass. Proc Natl Acad Sci U S A 106:5813-5818. 10.1073/pnas.0810550106

Prasad RB, and Groop L. 2015. Genetics of type 2 diabetes-pitfalls and possibilities. Genes (Basel) 6:87-123. 10.3390/genes6010087

Ravassard P, Hazhouz Y, Pechberty S, Bricout-Neveu E, Armanet M, Czernichow P, and Scharfmann R. 2011. A genetically engineered human pancreatic beta cell line exhibiting glucose-inducible insulin secretion. J Clin Invest 121:3589-3597. 10.1172/JCI58447

Salunkhe VA, Esguerra JL, Ofori JK, Mollet IG, Braun M, Stoffel M, Wendt A, and Eliasson L. 2015. Modulation of microRNA-375 expression alters voltage-gated $\mathrm{Na}(+)$ channel properties and exocytosis in insulin-secreting cells. Acta Physiol (Oxf) 213:882-892. 10.1111/apha. 12460

van Rooij E. 2011. The art of microRNA research. Circ Res 108:219-234. 10.1161/CIRCRESAHA.110.227496 


\section{Figure 1}

Experimental design and average cell-to-cell distance at harvest.

(A) Rat (INS-1832/13) and human (EndoC- $\beta \mathrm{H} 1$ ) insulin-secreting cell lines were seeded at different cell densities prior to downstream assays as outlined. (B) The average distance between cells at different harvest confluences for EndoC- $\beta \mathrm{H} 1$ cells. Data are presented as mean $\pm \mathrm{SEM}$ of $\mathrm{N}=40-90$ distance measurements from three independent seedings. (***) $p<0.001$; one-way ANOVA Tukey's multiple comparison test. 
A
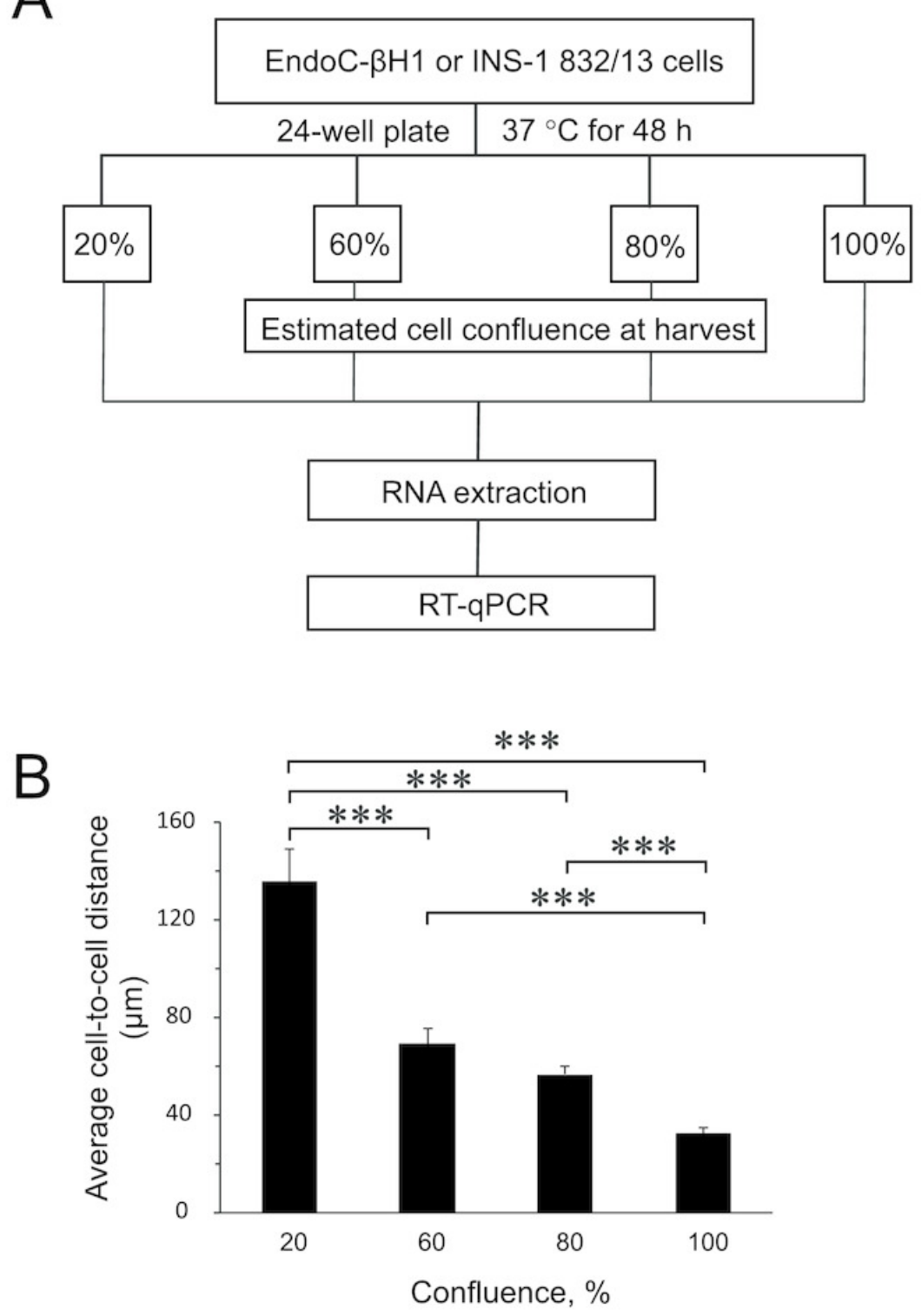


\section{Figure 2}

Expression of miR-375 and its targets in INS-1832/13 cells (A-C) or in EndoC- $\beta$ H1 cells (D-F).

(A) miR-375 expression at different cell confluence of INS-1 832/13 cells. Expression was normalized to rat U87. (B and C) Aifm1 and Cav1, expression in INS-1 832/13 cells, respectively. Expression were normalized to Hprt1 and Ppia. (D) Expression of miR-375 at different cell density in EndoC- $\beta \mathrm{H} 1$ cells. Expression was normalized to human RNU44 and RNU48. (E and F) AIFM1 and CAVI expression in EndoC- $\beta \mathrm{H} 1$ cells respectively according to cell density. Expression were normalized to HPRT1 and PPIA. For all experiments, data are presented as mean of $\mathrm{N}=3-4$ biological replicates, $(*) \mathrm{p}<0.05$ using one-way ANOVA Tukey's multiple comparison test. 

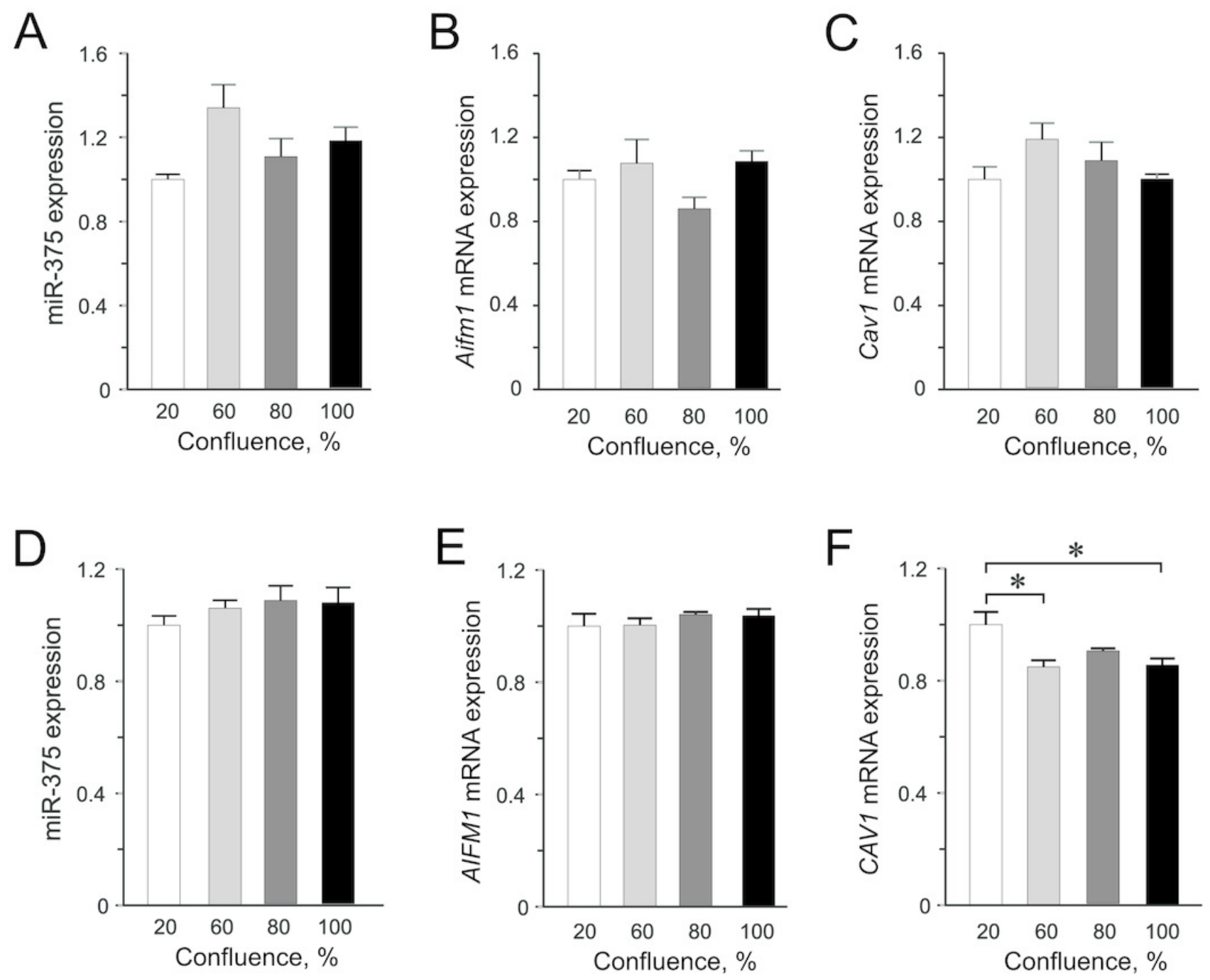


\section{Figure 3}

miR-132 and miR-212 expression in INS-1 832/13 cells (A-B) or in EndoC- $\beta$ H1 cells (C-D) at different confluences.

(A-B) INS-1 832/13 cells. (C-D) EndoC- $\beta$ H1 cells. Expression was normalized to rat U87 or to human RNU44 and RNU48. Data are presented as mean \pm SEM of $\mathrm{N}=3-4$ biological replicates. $\left(^{*}\right) p<0.05,\left({ }^{* *}\right) p<0.01,(* * *) p<0.001$; one-way ANOVA Tukey's multiple comparison test. 

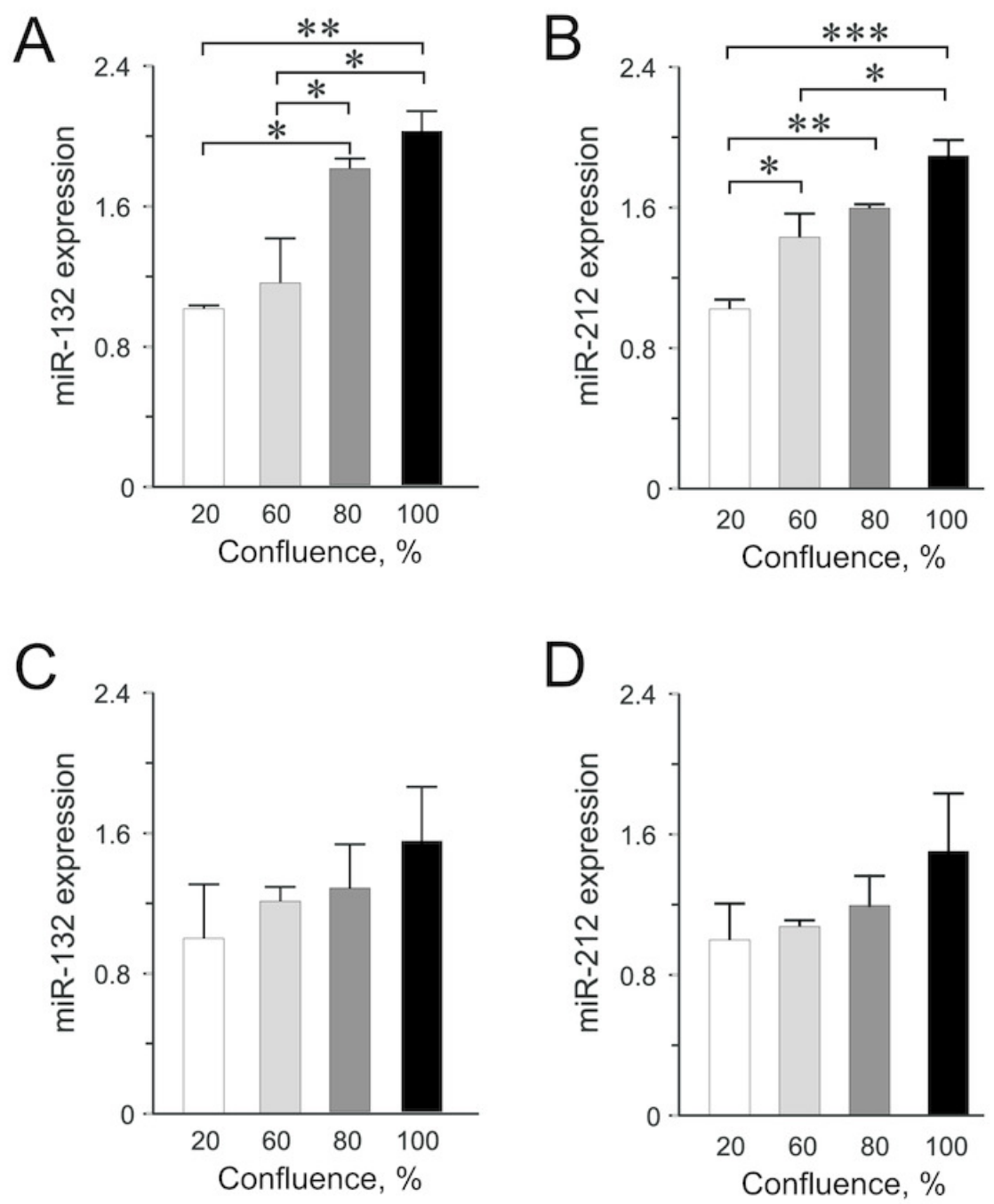